\title{
Los Ayuntamientos de los pueblos indígenas de Chiapas en el siglo XIX y su relación con los asuntos de justicia/
}

\author{
The Town Government in the Indigenous Townships \\ of Chiapas in the 19th Century and his Relation \\ with the Matters of Justice
}

\author{
María Dolores Palomo Infante \\ CIESAS Sureste, México
}

El surgimiento de los Ayuntamientos tras la promulgación de la Constitución gaditana de 1812, las nuevas corrientes ideológicas liberales decimonónicas, los cambios políticos producidos en México después de la Independencia y la necesidad de definir al nuevo Estado-nación, provocaron cambios en el ejercicio de la política y la justicia en los pueblos indígenas de Chiapas. Este artículo analiza de qué forma ejercieron los gobiernos locales sus funciones de impartición de justicia en aquellos pleitos que caían bajo su jurisdicción, y cómo participaron en algunos no como jueces sino como implicados en el proceso. Durante el siglo XIX, los Ayuntamientos de los pueblos indígenas de Chiapas fueron espacios conflictivos, donde se reconfiguraron el poder y la autoridad; espacios que estaban ahora mucho más diversificados desde el punto de visto étnico, con la existencia de un número cada vez mayor de ladinos en ellos, lo que determinó tanto los procesos jurídicos como políticos.

Palabras Clave: Ayuntamientos; Pueblos Indígenas de Chiapas; Justicia; Conflictos.

After the promulgation of the gaditanian Constitution in 1812, the formation of town governments, accompanied by new liberal ideologies and the political changes in newly independent Mexico directed to define the new State-Nation, impacted in the way politics and justice were practiced in the indigenous townships of Chiapas. This article analyzes the way how the town halls intervened in judicial affairs that were part of their jurisdiction, but as well as in some other cases as the accused. During the 19th century, the town governments in the indigenous townships resulted to be a competitive space in which power and authority were constantly restructured; a space much more diversified then with respect to ethnic composition, complemented by a constantly growing number of "ladinos", shaping political and judicial processes.

Keywords: Town Governments; Indigenous Groups en Chiapas; Justice; Conflicts. 
Con la independencia, se produjeron varios cambios en las relaciones de poder de los pueblos indígenas de Chiapas. Uno de los factores determinantes en este hecho fue el surgimiento de los Ayuntamientos constitucionales, que además de su incidencia en la arena política, se convirtieron en los órganos más cercanos de resolución de conflictos en el ámbito local. Esta institución, surgida tras la promulgación de la Constitución de Cádiz, se creo con el objetivo de administrar los asuntos locales y, como en su tiempo lo había sido el Cabildo, era ajena al gobierno indio que se había ido conformando y caracterizando paulatinamente a lo largo de tres siglos y configurando una nueva cultura política en los habitantes de los pueblos. Ante este nuevo escenario, determinado por el espíritu liberal del momento, se modificaron las condiciones de la vida política de las poblaciones indígenas y su posición dentro de los nacientes Estados nacionales. Fueron cambios que afectaron al ejercicio de la autoridad, a la representatividad india en las instituciones, a su condición jurídica y a las relaciones con la justicia, entre otros aspectos. ${ }^{1}$

En un intento de conjugar el estudio de las instancias de gobierno local y la situación de los indígenas en el Estado mexicano decimonónico, en este trabajo nos centraremos en el análisis de la participación de los Ayuntamientos en el ejercicio de la justicia y la resolución de los conflictos locales surgidos entre los individuos o grupos sociales; ${ }^{2}$ somos conscientes, no obstante, de que ésta es sólo una de las perspectivas desde la que se puede abordar este análisis.

El tema que nos ocupa no es nuevo en la historiografía mexicana y latinoamericana sobre la centuria decimonónica, particularmente si nos referimos a los Ayuntamientos y a los cambios políticos que se produjeron a raíz

1 La interpretación de estos cambios y de los efectos que el Estado nacional mexicano produjo en los pueblos indígenas es variable según los autores. Una visión bastante pesimista en la mayoría de los casos, puede verse en el denso y minucioso trabajo de Ferrer, Manuel y Bono, María: Pueblos indígenas y Estado nacional en México en el siglo XIX, Universidad Nacional Autónoma de México, [Serie C. Estudios Históricos, núm. 79], México, 1998; diferente es la interpretación de otros autores como Escobar Ohmstede, Antonio: "Los pueblos indios huastecos frente a las tendencias modernizadoras decimonónicas", en Escobar Ohmstede, Antonio; Falcón, Romana y Buve, Raymond (comps.): Pueblos, comunidades y municipios frente a los proyectos modernizadores en América Latina, siglo $X I X$, El Colegio de San Luis-Centro de Estudios y Documentos Latinoamericanos, México, 2002, págs. 169-184; o Falcón, Romana: México descalzo. Estrategias de sobrevivencia frente a la modernidad liberal, Plaza \& Janés, México, 2002, entre otros.

2 Cuando hablamos de resolución de conflictos nos referimos a los problemas que surgían en los pueblos con carácter inter o intraétnicos e inter o intracomunitarios, que necesitaban de la intervención de autoridades o instancias políticas con capacidad jurídica para solucionarlos. Los Ayuntamientos, y particularmente los alcaldes, tenían este tipo de competencias. 
de la Independencia de los diferentes países de América Latina; en los últimos tiempos ha crecido el interés de los historiadores por revelar las características generales y particulares de esta institución local en diferentes regiones culturales. Hay, no obstante, diversas visiones sobre su relevancia en los procesos políticos a partir del siglo XIX. Mientras que F.-X. Guerra opina que esta institución sufrió una disminución de influencia a partir de las Reformas Borbónicas, A. Annino defiende que los Ayuntamientos se vieron fortalecidos a partir de la Constitución de Cádiz y en varias ocasiones, a lo largo de tiempo, se enfrentaron con el Estado mexicano. ${ }^{3}$

Han sido varias las perspectivas desde las que se ha abordado el estudio de los Ayuntamientos, desde los autores que ponen su énfasis en el carácter legal, hasta los que lo sitúan en su relevancia política o económica. Desde nuestro punto de vista, y sin quitarle importancia a lo anterior, privilegiamos el aspecto social, aquel que se centra en analizar la importancia de la institución para la gente, para los grupos sociales, aquellos que la conformaban o aspiraban a formar parte de ella y aquellos que eran objeto de sus actuaciones, ya fueran criollos, ladinos o indígenas. En esta dirección apuntan varios trabajos que, centrados en ámbitos locales y regionales, nos muestran las peculiaridades de la institución en cada zona y que han confirmado la extraordinaria diversidad de situaciones, circunstancias y problemas que determinaron el devenir, el carácter y la relación de los gobiernos locales con los grupos de población. Muestran, asimismo, los ámbitos en los que intervino la institución y las reacciones de los diferentes actores sociales. ${ }^{4}$

3 Guerra, François-Xavier: "La desintegración de la monarquía hispánica: revolución e independencias", en Annino, Antonio; Castro Leyva, Luis y Guerra, François-Xavier (coords.): De los imperios a las naciones. Iberoamérica, IberCaja, Zaragoza, 1994, págs. 195-227; del mismo autor: México: del Antiguo Régimen a la Revolución, Fondo de Cultura Económica (FCE), México, 1995; Annino, Antonio: "Soberanías en lucha", en Annino, Castro Leyva y Guerra (coords.): De los imperios..., págs. 229-253; y del mismo autor: "Cádiz y la revolución territorial de los pueblos mexicanos 1812-1821", en Annino, Antonio (ed.): Historia de las elecciones en Iberoamérica, siglo XIX, FCE, México, 1995. En la misma línea podemos encontrar los trabajos de Buve, Raymond: "Una historia particular. Tlaxcala en el proceso del establecimiento de la primera república federal”, en Ortiz Escamilla, Juan y Serrano Ortega, José Antonio (eds.): Ayuntamientos y liberalismo gaditano en México, [Colección Debates], El Colegio de Michoacán-Universidad Veracruzana, Zamora, Mich., 2007, págs. 55-88.

4 De ello dan buena cuenta los artículos que se incluyen en el libro de reciente aparición, Ortiz Escamilla y Serrano Ortega (eds.), Ayuntamientos..., que muestran la diversidad del fenómeno municipal a través del análisis en diferentes regiones, centrados principalmente en el periodo de influencia directa de la Constitución gaditana, 1812-1814 y 1820-1824, así como en el primer federalismo mexicano. 
Un aspecto que nos interesa es el análisis regional, que nutra esta diversidad historiográfica y muestre las peculiaridades de la institución en Chiapas, entre los pueblos chiapanecos; en algunas regiones de México, la creación de Ayuntamientos en los primeros años posteriores a la Constitución gaditana fue explosiva, lo que constituyó una verdadera revolución local, ${ }^{5}$ aunque las circunstancias políticas, económicas y sociales posteriores y al amparo legislativo, modificaron la tendencia inicial. ${ }^{6}$ Sin embargo, en Chiapas el proceso, a priori, parece algo diferente, al menos en el periodo inicial; aunque también es cierto que a lo largo de la centuria fue cambiando la fisonomía jurídico-territorial del Estado, mediante la creación de nuevos municipios con derecho a tener Ayuntamiento. Sólo algunos de estos proyectos prosperaron, mientras que otros, por diferentes circunstancias, tuvieron que abandonar la categoría que les daba el derecho a tener gobierno municipal. ${ }^{7}$

El otro punto de interés es el análisis que privilegia a los sujetos sociales, cómo se vieron afectados por esta institución y por los cambios jurídicos liberales, particularmente la población indígena, y cuáles fueron sus respuestas. ${ }^{8}$ Pensamos que los indígenas no fueron objetos pasivos frente al Estado decimonónico, sino que supieron y pudieron encontrar diversas vías estratégicas con las cuales enfrentarse a las cambiantes circunstancias, como habían hecho desde antiguo. Esta discusión se da dentro de la problemática que generó la relación entre la población indígena y el Estado Nación en un proceso que tenía dos caras: por una parte "domesticar" la diversidad cultural que pretendía homogeneizar ${ }^{9}$ un Estado en constante definición y, por la otra, no ser olvidados ni desaparecer de la historia del

5 Varios autores han analizado esta revolución; el máximo exponente es Antonio Annino.

6 Pueden consultarse los trabajos contenidos en Ortiz Escamilla y Serrano Ortega, (eds.), Ayuntamientos...

7 Una de las razones era el descenso del número de habitantes. Hay casos en los que se le dio la categoría de municipio a un núcleo de población, pero posteriormente no aparece ningún registro del mismo, por lo que podemos suponer que no llegó a concretarse nunca su calidad de municipio. Un ejemplo fue Saclamenton y Nuevo Edén, que en 1862 fueron declarados pueblos del Estado, y posteriormente los encontramos como poblaciones de Chamula. Archivo Histórico del Estado (en adelante AHE), Fondo Castañón y Gamboa, Expediente 251.

8 Es importante para este análisis el contexto que ofrece Escobar Ohmstede: "Los pueblos indios huastecos...”, págs. 169-184.

9 Sobre el proceso de homogeneización en la conformación de las naciones, puede consultarse Quijada, Mónica; Bernand, Carmen y Schneider, Arnd: Homogeneidad y Nación, con un estudio de caso: Argentina, siglos XIX y XX, Consejo Superior de Investigaciones Científicas [Colección Tierra Nueva e Cielo Nuevo], Madrid, 2000. 
país. ${ }^{10}$ Varios autores han profundizado sobre este aspecto desde diferentes perspectivas. En un contexto que tenía como fondo el dominio y enfrentamiento entre grupos dominantes y subalternos, R. Falcón recoge varias estrategias de los pueblos indígenas de diferentes regiones de México, para concluir que éstos últimos "utilizaron los conceptos y las instituciones de la modernización como un menú a la carta de acuerdo a sus necesidades concretas y entreverándolo con sólo aquellas partes del pasado que les convenía preservar". ${ }^{11}$

En lo que no todos los autores coinciden fue en el tipo de estrategias utilizadas; por ejemplo, M. Ferrer y M. Bono retoman los ejemplos de insurrecciones y revoluciones como las vías elegidas por estas poblaciones. ${ }^{12}$ Sin embargo, en la historia decimonónica de Chiapas, apenas se dieron dos alzamientos. ¿A qué se debió entonces que la rebelión no fuese la primera opción para los indígenas chiapanecos? Fueron varias las razones, pero nos inclinamos por la que se considera que fue la primera opción legal a la que acudieron los pueblos para hacer valer sus derechos.

Para mostrar lo anterior, analizaremos algunos casos relacionados con el conflicto social y el ejercicio de la justicia, particularmente de la segunda mitad del siglo XIX, que ilustran diferentes características de la relación de las instituciones políticas y los individuos con la práctica jurídica a un nivel local. ${ }^{13}$ La ideología liberal en el siglo XIX ${ }^{14}$ pretendía la eliminación

10 Ferrer y Bono: Pueblos indígenas... El análisis de estos autores permite conocer varios ejes a través de los cuales se desarrolló esta relación, desde lo político a lo jurídico, pasando por lo étnico. Algunas de las conclusiones a las que llegan pueden ser cuestionables o matizadas, pero es un buen ejercicio analítico.

11 Falcón: México descalzo..., pág. 21. Reina y Velasco muestran cómo las poblaciones indígenas se movieron estratégicamente entre la revolución, en un primer momento, y la reindianización a finales de siglo. Reina, Leticia y Velasco, Cuauhtémoc: "Introducción", en Reina, Leticia (coord.): $L a$ reindianización de América, siglo XIX, Editorial Siglo XXI-Centro de Investigaciones y Estudios Superiores en Antropología Social (CIESAS), México, 1997.

12 Ferrer y Bono: Pueblos indígenas...; en la misma línea se ubica el trabajo de Reina, Leticia: Las rebeliones campesinas en México, 1819-1906, Editorial Siglo XXI, México, 1984.

13 Sabemos que en la institución municipal no se finiquitaban todos los casos de conflicto, sino que existían otras instancias superiores encargadas de ello, con las cuales el Concejo tenía relaciones. Sin embargo, nuestro objetivo no es analizar el sistema judicial en su conjunto, sino este primer nivel de resolución de situaciones de conflicto. Es interesante el trabajo de Morelli, quien afirma que "la justicia tiene una importancia estratégica en la transformación del municipio hispanoamericano en un poder autónomo y soberano con respecto al Estado" además de que promovió la continuación de "una cultura jurisdiccional tradicional, que unía en un solo cuerpo justicia y gobierno" y que en algunos casos se prolongó a lo largo de todo el siglo XIX. Morelli, Federica: "Pueblos, alcaldes y municipios: la justicia local en el mundo hispánico entre Antiguo Régimen y Liberalismo", Historia Critica, Núm. 36, Bogotá, julio-diciembre 2008, pág. 52-53; Annino también resalta la importancia de la justicia en la concreción de la autonomía del municipio, poniendo de relieve la figura de los jueces de paz. 
de barreras étnicas, igualando legalmente a todos los habitantes de la Nación; la creación de los Ayuntamientos constitucionales en cierta medida era un mecanismo para ello, al representar los intereses de todos los vecinos de un mismo pueblo. Sin embargo, las diferencias reales eran notables. Desde finales del siglo XVIII, la fisonomía étnica de los pueblos de indios en Chiapas se acercaba más a su ladinización y la posición social, política y económica de la mayor parte de la población autóctona se vio afectada. Podemos preguntarnos si, verdaderamente, el Ayuntamiento fue una instancia que representaba a todos los habitantes de los pueblos y si los indígenas se sentían identificados con el Ayuntamiento constitucional. En cuanto a los asuntos de justicia ¿cómo y en qué dirección actuó ese Ayuntamiento constitucional a la hora de los conflictos? ¿De qué se valían los indígenas para hacer valer sus derechos? ¿Qué instrumentos utilizaban? ¿El propio Ayuntamiento? ¿Y si este era ladino? Desvelar esta relación y ver algunas de las formas mediante las cuales la población autóctona se adaptó a las nuevas circunstancias es uno de los objetivos de este trabajo.

En ambos lados, es decir, en el de la institución municipal y en el de la población, cabría preguntarse sobre qué tan importante y definitorio era, en este nuevo contexto ideológico, el factor étnico, tanto en la actuación de los Ayuntamientos como en el comportamiento de los individuos o grupos de población; es decir, si las decisiones se tomaban por ser indígenas o por

Annino, Antonio: "Ciudadanía versus Gobernabilidad republicana en México", en Sábato, Hilda (coord.): Ciudadanía política y formación de las naciones. Perspectivas históricas en América Latina, [Sección de Obras de historia, Serie Ensayos], Fideicomiso Historia de las Américas, FCE, México, 1999, págs. 62-93. Entre otros autores que han trabajado sobre este tema, podemos destacar a Bellingeri, Marco: "Sistemas jurídicos y codificación en el primer liberalismo mexicano, 1824-1834", en Bellingeri, Marco (coord.): Dinámicas de Antiguo Régimen y orden constitucional: representación, justicia y administración en Iberoamérica, siglos XVIII-XIX, Otto Editore, Turín, 2000, págs. 367-395; Argeri, María: De guerreros a delincuentes. La desestructuración de las jefaturas indígenas y el Poder Judicial. Norpatagonia, 1880-1930, CSIC, Madrid, 2005.

14 Cuando hablamos de liberalismo, de ideología liberal o de prácticas liberales somos conscientes de que hablamos de un proceso; es decir, ni lo colonial desapareció de golpe, ni la modernidad entró sin llamar a la puerta. Estamos de acuerdo con Ducey cuando habla de "una complicada dualidad dentro del nuevo orden" en la que el nuevo lenguaje que se empezaba a generalizar, a diferentes ritmos según las regiones, no logró acabar de golpe con la tradición colonial de los pueblos indígenas. Ducey, Michael T.: "Indios liberales y liberales indigenistas: ideología y poder en los municipios rurales de Veracruz, 1821-1890", en Escobar Ohmstede, Antonio y Carregha Lamadrid, Luz (coords.): El siglo XIX en las Huastecas, [Colección Huasteca], Centro de Investigaciones y Estudios Superiores en Antropología Social-El Colegio de San Luis, México, 2002, pág. 143. En este mismo sentido argumenta Carmen Salinas, para quien los Ayuntamientos combinaron características del Antiguo Régimen y del liberalismo. Salinas Sandoval, María del Carmen: "Ayuntamientos en el Estado de México, 18121827. Proceso de adaptación entre el liberalismo y el Antiguo Régimen”, en Ortiz Escamilla y Serrano Ortega, (eds.), Ayuntamientos..., págs. 369-410. 
ser ciudadanos. Por ejemplo, en relación a la normatividad y la administración de justicia, ahora era el derecho positivo nacional el que regía los procesos judiciales. Para los indígenas ese era también "su derecho", como ciudadanos que eran, pero estaba muy alejado del consuetudinario, de las formas propias de ejercer justicia. Pero lejos de pensar que esto supuso una grave amenaza para ellos como han defendido varios autores, ${ }^{15}$ creemos que se apropiaron estratégicamente de esa legislación que, por otra parte, tenía algunos reductos normativos a su favor que fueron aprovechados llegada la ocasión, y sobre ello incidiremos en este artículo. ${ }^{16}$

Este trabajo tendrá un recorrido diacrónico por la centuria decimonónica; para el análisis de los casos de conflicto se centra en la segunda mitad del siglo, por dos razones: la primera está relacionada con el acceso a la información. Hasta el momento, la documentación que hemos consultado es bastante discontinua, lo que impide valorar en profundidad los diferentes momentos o periodos relativos al carácter de los pueblos, su población y los Ayuntamientos; ${ }^{17}$ la segunda, que manejamos todavía a manera de

15 Entre ellos Ferrer y Bono, Pueblos indígenas..., págs. 261-263.

16 Cuando los casos eran juzgados por los Ayuntamientos, la resolución no dependía tanto de la ley como de la cabalidad de los alcaldes. Morelli: "Pueblos, alcaldes y municipios...". Una muestra sobre cómo accedieron los pueblos indígenas a los sistemas judiciales la tenemos en varios trabajos contenidos en el libro de Roth Seneff, Andrew (ed.): Recursos contenciosos. Ruralidad y reformas liberales en México, [Colección Investigaciones], El Colegio de Michoacán, Zamora, Mich., 2004.

17 El trabajo que presentamos es un acercamiento inicial, debido a que esta investigación apenas está en sus comienzos y falta obtener y sistematizar más información para documentar de forma más sólida nuestros argumentos. Sin embargo, los casos que incluimos son significativos para lo que queremos demostrar. Desafortunadamente, existen muchas dificultades para consultar los archivos municipales de Chiapas. En muchos casos, su estado de conservación es deplorable; en otros, la oposición de las autoridades municipales, especialmente de los secretarios, hace imposible el acceso a la información. La historiadora Rocío Ortiz dice que el funcionamiento de los Ayuntamientos en Chiapas fue intermitente, obedeciendo a diferentes disposiciones determinadas por las luchas entre liberales y conservadores (Ortiz, Rocío: Pueblos de indios, iglesia católica y élites políticas en Chiapas. 18241901. Una perspectiva histórica, Consejo Estatal para la Cultura y las Artes de Chiapas, Tuxtla Gutiérrez, 2003, págs. 193-209); esta es otra de las razones por las cuales la documentación es discontinua. En el AHE hemos consultado las fuentes con datos sobre las funciones de los Ayuntamientos en la legislación, para cuestiones de normativa, y en las actas de Cabildo, para conocer el día a día de esta institución-y sobre su papel en la resolución de conflictos, en los documentos generados por los Ayuntamientos como juzgados locales que eran — como por ejemplo, en las actas de conciliación-y en las comunicaciones que éstos mantenían con los Juzgados de primera instancia. En cuanto a su papel como parte en los conflictos, es decir, como promotor de pleitos en defensa de los intereses de los pueblos, o simplemente como testigo en alguno de los juicios, la información que utilizamos procede del Archivo de la Casa de la Cultura jurídica — en adelante AJD— donde se conservan los pleitos que se elevaban al Juzgado de Distrito y a la Suprema Corte de Justicia y allí hemos consultado los procesos de denuncios de tierras. Por último, otra fuente importante han sido los pleitos que se localizan en el Archivo Histórico Judicial de San Cristóbal de las Casas —en adelante AHJSC_-. 
hipótesis, es que en el marco cronológico que consideramos en esta investigación, se habían asentado de forma más sólida tanto el desempeño de los gobiernos locales como las relaciones entre las instituciones políticas y los individuos y/o comunidades dentro de la conformación del Estado-Nación; por otra parte, la larga experiencia obtenida a lo largo de medio siglo, le había permitido a la población indígena desarrollar estrategias para enfrentarse a las nuevas situaciones e instituciones nacionales.

\section{Los pueblos y sus habitantes}

La vida de los Ayuntamientos estuvo unida inevitablemente a la de los pueblos. Por ello, es necesario hacer una breve descripción de éstos y de sus habitantes para entender y contextualizar su trayectoria. Nos interesa resaltar los cambios en el perfil étnico y político de los espacios territoriales en los que se desarrollaron las idas y venidas de esos Ayuntamientos. Este trabajo se centra en los pueblos tzeltales y tzotziles de Chiapas, ${ }^{18}$ y se basa en la información obtenida de algunos de los más importantes, bien por su número de población, bien por su relevancia económica y política, como Ocosingo, Comitán, Zapaluta y Huistán.

Los pueblos de Chiapas se conformaron la mayoría de ellos en los procesos de congregaciones que la Corona llevó a cabo en el siglo XVI. La organización socio-territorial, política y jurídica de la población autóctona durante la época colonial se basó en la fundación de pueblos de indios, en la instalación del Cabildo como fórmula de organización política y en la creación de la república de indios, que provocó la separación física y jurí-

18 Utilizamos el nombre actual de estos grupos indígenas debido a la diversidad de denominaciones con las que se les nombró a lo largo de la colonia: zozil, sotsil quelenes, entre otros a los tzotziles y cendales, sendales, zeltales a los tzeltales; también fueron diversos los nombres de las demarcaciones territoriales a las que pertenecían — provincias, subdelegaciones, partidos o departamentos, dependiendo de la época- . Estas denominaciones pudieron derivarse de la lengua que se hablaba en cada pueblo, ambas de filiación maya, lo que fue aprovechado por la política colonial para crear sus unidades administrativas. Tras la Independencia, desaparecen estas identificaciones, acorde con el espíritu de igualdad jurídica liberal, para reaparecer a inicios del siglo XX. Cuando hablamos de "pueblos" nos referimos a los núcleos de población ubicados en un espacio territorial con la categoría jurídica de municipio, compuesto de una cabecera municipal y diferente número de parajes o rancherías y habitado por una mayoría de población indígena que se reconoce y es reconocida como perteneciente a estos grupos étnicos. En términos de la regionalización realizada por Viqueira, estamos hablando de los pueblos localizados en las Montañas Mayas — que incluyen las Montañas Zendales- y los Llanos de Comitán. Viqueira, Juan Pedro: Encrucijadas chiapanecas: economía, religión e identidades, El Colegio de México- Tusquets Editores México, México, 2002. 
dica con respecto a los colonizadores españoles. Los pueblos quedaron conformados por una cabecera política y un número variable de parcialidades, que en cierto modo eran los emblemas de la identidad de cada uno de los grupos congregados. Todas participaban en el Cabildo indio.

Los pueblos de indios a los que nos referimos estuvieron habitados sólo por nativos durante toda la colonia, debido a las limitaciones que tanto la Corona como los dominicos pusieron al resto de la población para vivir en ellos. Esto permitió que, a pesar de la influencia que los colonizadores ejercieron en el funcionamiento del Cabildo, su composición fuera íntegramente indígena, lo que en cierto modo permitió la "autonomía" de esta institución, de las autoridades indígenas y de los mismos pueblos de indios.

Después de los altibajos demográficos que hubo en Chiapas durante la colonia, el siglo XVIII fue un periodo de recuperación demográfica para la población indígena. Para inicios del XIX, había alcanzado una estabilidad que se mantendría a lo largo de la centuria. En 1814, el $81 \%$ de los habitantes del Estado eran indígenas, predominando en la mayoría de los pueblos. ${ }^{19}$ No obstante, hubo algunos que desde temprano vivieron un proceso de ladinización, como Ocosingo y Comitán, incluso desde finales del siglo XVIII. Otros, en cambio, continuaron siendo íntegramente indígenas, no obstante que a lo largo del XIX comenzaron a contar con un porcentaje variable de población ladina. Esto marcó las características de la institución municipal en ellos y las relaciones socio-políticas entre ésta y sus habitantes. La ladinización se debió a razones biológicas (proceso de mestizaje) migratorias (establecimiento de mestizos y/o españoles en los pueblos procedentes de otros lugares, por ejemplo Ciudad Real de Chiapa) y culturales (diferentes formas de entender el término ladino y autoadscripción del individuo) Esta última fue la vía que permitió a los indígenas cambiar su identidad si así convenía a sus intereses.

Es necesario hacer una aclaración con respecto al término ladino que, aunque en esencia significaba lo mismo en el siglo XVII que a finales de la colonia y en el siglo XIX, existen algunas diferencias contextuales. Así, en los documentos encontramos un testimonio de 1615 , en el que se tilda a las autoridades de una de las parcialidades de Coapa, Tepiencoapa - alcalde, principales, regidor y cabeza de calpul - como ladinos. ${ }^{20}$ Es decir, son

19 Ibidem, pág. 263.

20 Archivo General de Indias, Sevilla (en adelante AGI), Audiencia de Guatemala, 97, N. 31. 28 de marzo de 1615. Expediente de confirmación de encomienda de Iztacomiclan, Bitilan, Oiexcuatlan, Ocotitlan, Tepiencoapa, y Zitalazitaclan en Chiapa a Pedro de Eizaguirre. 
indios y además autoridades, pero son ladinos en el sentido de que saben hablar el castellano y además saben firmar. Mientras tanto, a finales del siglo XVIII y durante el XIX, el término ladino adquirió un contenido distinto, siendo ladino todo aquel que no era indígena, que no se identificaba o no era identificado como tal y que no procedía de acuerdo a los criterios que definían la vida en comunidad; justo una comunidad que el Estado y la legislación tenían el objetivo de eliminar.

Desde el final de la colonia, los pueblos que tenían potencial económico - particularmente buenas tierras - recibieron la llegada de ladinos con la intención de explotar sus recursos, por lo que poco a poco se fueron ladinizando. Estos núcleos adquirieron importancia política, ya que por lo general se convirtieron en cabeceras de distrito o departamento, según la época. Por la presencia ladina, los indígenas fueron desplazados de los cargos municipales que acapararon los primeros debido, entre otras razones, a una supuesta mejor preparación y "calidad" social, según los criterios de ciudadanía — saber leer y escribir era importante para ocupar un cargo concejil-; asimismo, se debió a que los ladinos reclamaron derechos en los pueblos para defender mejor sus intereses, sobre todo económicos, y a que la legislación permitió su inclusión en el concejo municipal. ${ }^{21}$ En los pueblos ladinizados fue en los que se puso a prueba la convivencia entre los diferentes grupos de población ya que, aunque los conflictos no atendían criterios de raza, etnia o condición social, los choques fueron más significativos cuando se producían entre "indios" y "ladinos".

\section{Los Ayuntamientos en Chiapas: su establecimiento y características}

La Constitución de Cádiz disponía que "para el gobierno interior de los pueblos habrá Ayuntamientos, compuestos del alcalde o alcaldes, los regidores y el procurador síndico y presididos por el jefe político, donde lo hubiere, y en su defecto por el alcalde o el primero nombrado entre éstos,

21 Esto nos remite a la discusión sobre la ciudadanía que determinó la participación política de los individuos. Fue importante definir quién podía ser ciudadano, qué condiciones y requisitos debía cumplir, lo que, en principio, le otorgaba o negaba determinadas obligaciones y derechos políticos. Remitimos al lector a los artículos que contienen los siguientes trabajos: Annino: Historia de las elecciones...; Sábato (coord.): Ciudadanía política ...; Irurozqui, Marta: La mirada esquiva. Reflexiones históricas sobre la interacción del Estado y la ciudadanía en los Andes (Bolivia, Ecuador y Perú), siglo XIX, CSIC, Madrid, 2005. Escobar Ohmstede, Antonio: "Ayuntamientos y ciudadanía, formas de administración de poblaciones”, en Ortiz Escamilla y Serrano Ortega, (eds.), Ayuntamientos..., págs. 131-172. 
si hubiere dos", ${ }^{22}$ Nacía con ello el Ayuntamiento constitucional, como institución administrativa y de gobierno en el ámbito local, y desaparecía legalmente el Cabildo colonial que durante trescientos años había "regido" la vida política en los pueblos del Nuevo Mundo y había configurado, junto con otras instituciones como las cofradías, la cultura política en los pueblos de indios. Sus cargos y sus prácticas políticas habían consolidado a lo largo del periodo colonial un gobierno indio en sus territorios. ${ }^{23}$ Sin embargo, pensamos que en algunos pueblos, se mantuvieron durante varios años más ciertas formas de autoridad autóctona bajo fórmulas encubiertas o más o menos informales desde el punto de vista legal, pero con un gran peso político para los indígenas, ${ }^{24}$ situación que se mantiene hasta hoy.

El decreto 97 de 23 de mayo de 1812, argumentaba la creación de los Ayuntamientos por el bien y tranquilidad de las familias y la prosperidad de la nación, en ese entonces todavía la española. ${ }^{25}$ No sabemos exactamente cuántos y cuáles fueron los Ayuntamientos que se fundaron en los pueblos chiapanecos durante la vigencia de la Constitución de Cádiz. Para otras regiones de México tenemos estudios que confirman su conformación entre 1812 y 1814 y posteriormente en 1820, una vez restablecida la Carta Magna gaditana. ${ }^{26}$ En cualquier caso, estaríamos ante la presencia de instituciones todavía coloniales, anteriores a la Independencia. Según refiere M. H. Ruz, ${ }^{27}$

22 Art. 309 de la Constitución de Cádiz de 1812. Recurso electrónico: Dirección: http://www.congreso.es/constitucion/ficheros/historicas/cons_1812.pdf

23 M. Ferrer y M. Bono opinan que la creación de Ayuntamientos condenó a muerte a los Cabildos indígenas, últimos reductos de la autonomía política de los pueblos. Ferrer y Bono, Pueblos indígenas..., págs. 378-386.

24 Ver por ejemplo, Hernández Chávez, Alicia: La tradición republicana del buen gobierno, El Colegio de México- FCE, México, 1993; Ducey: "Indios liberales...", págs. 111-136; Guardino, Peter: " 'Toda la libertad para emitir sus votos". Plebeyos, campesinos y elecciones en Oaxaca, 18081850", en Cuadernos del Sur, núm. 6/15, Oaxaca, 2000, págs. 87-114; del mismo autor: "El nombre conocido de república. Municipios en Oaxaca, de Cádiz a la primera república federal”, en Ortiz Escamilla y Serrano Ortega (eds.), Ayuntamientos..., págs. 213-234.

25 Decreto 97 de 23 de Mayo de 1812: "Formación de los ayuntamientos constitucionales", en Dublán, Manuel y Lozano, José María: Legislación mexicana o colección completa de las disposiciones legislativas expedidas desde la Independencia de la República. Recurso electrónico. Dirección: http://biblioweb.dgsca.unam.mx/dublanylozano/

26 Escobar Ohmstede, Antonio: "Del gobierno indígena al Ayuntamiento constitucional en las Huastecas hidalguense y veracruzana, 1780-1853”, Mexican Studies/Estudios Mexicanos, Vol. 12, Núm. 1, 1996; Hernández Chávez: La tradición republicana...; también los trabajos contenidos en Ortiz Escamilla y Serrano Ortega, (eds.), Ayuntamientos... muestran este proceso a lo largo y ancho de la República Mexicana.

27 Ruz Sosa, Mario Humberto: Savia India, floración ladina. Apuntes para una historia de las fincas comitecas (siglos XVIII y XIX). Consejo Nacional para la Cultura y las Artes, México, 1992, págs. 134-146. 
los ladinos de Comitán hicieron en 1820 la elección para conformar un Ayuntamiento constitucional, independiente del Ayuntamiento indio. Parece ser que fue uno de los únicos que se crearon a consecuencia de la aplicación de la Constitución de Cádiz. La cuestión es que en Comitán, en 1821, hubo dos gobiernos locales diferenciados, uno de ladinos y otro de indios. Este último, en aras del espíritu constitucional, fue disuelto poco después por órdenes de la Audiencia de Guatemala.

De la información que tenemos, en Chiapas no empiezan a funcionar sino hasta la década de 1820 los más precoces. ${ }^{28}$ El 30 de noviembre de 1825, el excelentísimo gobernador del Estado de Chiapas decretó y mandó publicar la Ley reglamentaria de Ayuntamiento. ${ }^{29}$ El 10 de enero de 1825, "estando en cabildo" se juró la Constitución de los Estados Unidos mexicanos en el pueblo de Teopisca, acto al que concurrieron "todos los vecinos de este pueblo y los de los anexos de Amatenango y Aguacatenango"; unos días antes, el 27 de diciembre del año anterior, en un acto similar, realizó el juramento el Ayuntamiento de San Miguel Pinola. También tenemos constancia de la celebración de elecciones municipales en diciembre de 1825 en Soyatitán, y en el mismo mes, pero un año después, en Santa Cruz Sosocoltenango.$^{30}$ Ortiz argumenta que la vida de los Ayuntamientos en Chiapas fue intermitente durante la primera mitad del siglo XIX, atendiendo a las cambiantes circunstancias políticas estatales y a la alternancia entre liberales y conservadores. En 1858, el gobernador Ángel Albino Corzo los restableció, ya que habían sido eliminados durante el periodo conservador, y a partir de ahí no volvieron a ser suprimidos. ${ }^{31}$

Aunque la legislación normaba el funcionamiento de la institución de gobierno municipal, la práctica diaria modificaba el sentido de las leyes. Sabemos que una de sus principales funciones fue la impartición de justi-

28 Rocío Ortiz dice que los primeros Ayuntamientos constitucionales comenzaron a funcionar en Chiapas en 1826, con la promulgación de la Constitución de ese mismo año. Ortiz: Pueblos de indios..., pág. 194.

29 AHE, Fondo Archivo Histórico de Comitán, Presidencia Municipal, 1825.

30 Ibidem, 1826. Como ya apuntábamos más arriba, en Chiapas no se produjo una explosión municipal, ya que no se crearon una gran cantidad de Ayuntamientos como había sucedido en otras regiones de México en las que se había duplicado y triplicado el número de ellos. En el siglo XIX Chiapas modificó su división político-administrativa a través de varios cuerpos legislativos como la Constitución Política del Estado de Chiapas de 1826, de 1858, de 1880 — que introduce reformas a la anterior-y de 1893, así como varios decretos que enmarcaron jurídicamente los movimientos jurisdiccionales del territorio y la administración política en ella, lo que afectó de manera particular al funcionamiento de los Ayuntamientos. Instituto Nacional de Estadística y Geografía: División territorial del estado de Chiapas de 1810 a 1995, Instituto Nacional de Estadística y Geografía, México, 1997.

31 Ortiz: Pueblos de indios..., pág. 200. 
cia. Por esta razón, en algunos casos se fundaron en pueblos que no alcanzaban el número necesario de habitantes. ${ }^{32}$ En cuanto a las características que debían tener los pueblos para conformar Ayuntamiento, para Chiapas sólo aparecen en la Constitución estatal de 1826, desapareciendo en las posteriores esta información, no obstante que era competencia de los gobiernos estatales normar este aspecto, ${ }^{33}$ que fue regulado por diferentes decretos.

Una diferencia entre los Ayuntamientos y los Cabildos coloniales es que estos últimos existieron en todos los pueblos; cabeceras y parcialidades tuvieron sus autoridades locales, representantes de su población en el Cabildo. Así se entiende del hecho de que en el acto de posesión de encomienda de la parcialidad de Tepiencoapa, en 1613, se hallaran presentes el alcalde de la parcialidad, los principales y el cabeza de calpul. ${ }^{34}$ Con los Ayuntamientos constitucionales algunos pueblos perdieron su derecho a autogobernarse, ya que sólo las cabeceras tuvieron la oportunidad de conformar legalmente un gobierno municipal, aunque continuaron teniendo autoridades propias, comunitarias que, pese a no estar legalmente reconocidas, si tenían una gran fuerza moral.

Pero la diferencia más importante entre los Cabildos y los Ayuntamientos fue el cambio en cuanto al concepto de gobierno, resultado del contexto ideológico. El funcionamiento de los primeros se dio hasta finales del siglo XVIII en la lógica de la política colonial, bajo un concepto de gobierno corporativo, cuyo objetivo era conducir la vida de los pueblos para lograr el bien público y la conservación de los derechos colectivos. En contraste, el Ayuntamiento era una instancia de administración municipal, representante de la soberanía de la sociedad civil. ${ }^{35}$

Como señalábamos más arriba, un elemento que intervino en las características de los Ayuntamientos en Chiapas fueron los procesos de

32 En la Constitución de Chiapas de 1826, en el artículo 25 que normaba el gobierno político de los pueblos, dice: "Para el gobierno interior de los pueblos habrá ayuntamientos elegidos popularmente en todos los que tengan el número de mil almas a lo menos; o aunque sea menor su población, si así lo exigen sus circunstancias". Constitución Política del Estado de Chiapas, 1826.

33 Escobar Ohmstede, "Del gobierno indígena...".

34 AGI, Audiencia de Guatemala, 97, N. 31, 28 de marzo de 1615. "Confirmación de encomienda de Iztacomitlan, Bitilan, Oiexcuatlan, Ocotitlan, Tepiencoapa, y Zitalazitaclan en Chiapa a Pedro de Eizaguirre".

35 Lemperiere, Annick: "Reflexiones sobre la terminología política del liberalismo", en Connaughton, Brian; Illades, Carlos y Pérez Toledo, Sonia: Construcción de la legitimidad política en México, El Colegio de Michoacán-Universidad Autónoma Metropolitana-Universidad Nacional Autónoma de México-El Colegio de México, México, 1999, págs. 35-56. 
ladinización de los pueblos. Esto fue importante en tanto que esta población no india, acaparó el poder en las instancias políticas locales, lo que determinó la conformación y el carácter del Ayuntamiento, y de ello dependieron también las posibilidades de la población indígena de acceder a los núcleos de poder y ejercicio de la autoridad. La ocupación de cargos de Cabildo por ladinos había estado restringida hasta entonces; sin embargo, con la igualdad jurídica posindependentista, tuvieron el camino libre para acceder a los puestos municipales. Surgió con ello una alcaldía mixta, ${ }^{36}$ al menos en algunos pueblos. Por ejemplo, el Ayuntamiento de Ocosingo, entre 1830 y 1834, estaba compuesto por regidores ladinos e indígenas. En 1835, un acta de elección decía: “....acto continuo siendo los ciudadanos José Alejo Hidalgo, Eugenio Estrada y Francisco Burguete en el salón de la casa consistorial de esta villa, cuyo número de electores son 3 por haberse exceptuado los de la municipalidad indígena...". ${ }^{37}$ Estos documentos nos hablan de una separación del carácter étnico de las municipalidades. No creemos que hubiera dos Ayuntamientos funcionando separadamente; más bien, nos inclinamos a pensar que era una municipalidad mixta, compuesta de ladinos e indígenas. Más tarde, en 1869, encontramos que los alcaldes indios auxiliares del pueblo de Ocosingo estaban exentos del pago del impuesto de capitación, condición que compartían con los miembros del Ayuntamiento, los jueces locales, los jueces rurales y los militares: es decir, encontramos que había autoridades indígenas que ocupaban un cargo concejil dentro de los Ayuntamientos ladinizados. ${ }^{38}$

Ahora bien, los cargos concejiles, efectivamente, suponían una carga para quienes los ocupaban; no en vano en las actas de Cabildo se repiten las solicitudes de licencias para abandonar temporalmente el cargo que realizan los electos y la normatividad que la legislación tenía referente a los periodos que podían ausentarse del cargo.$^{39}$ Por lo tanto, podemos pregun-

36 En el caso de Guatemala, ver Barrios, Lina: La alcaldía indígena en Guatemala: de 1821 a la revolución de 1945, Universidad Rafael Landívar, Guatemala, 1998.

37 AHE, Fondo Castañón y Gamboa, Expediente 037. Actas de las sesiones ordinarias y extraordinarias. Ocosingo. 1835.

38 Ibidem, Expediente 377.

39 La Constitución política del Estado de Chiapas de 1858, en el artículo 12, sección 3. a , en la que se habla de los deberes de los ciudadanos chiapanecos, dice que uno de estos deberes es: "Desempeñar los cargos públicos sin poder rehusarse sino en casos de impedimento grave á juicio de autoridad competente". Constitución Política de Chiapas, 1858. Más tarde en 1860, un decreto del gobernador Ángel Albino Corzo determina que "los alcaldes no se separarán del desempeño de sus funciones sin licencia escrita de los jueces de primera instancia, ni esta podrá exceder de los tres meses que les concede la ley en cada año". AHE, Colección impresos, tomo 17. Nuevamente se insiste en ello 
tarnos ¿qué ventajas tenía ocupar ese cargo, si no era la posibilidad de defender los intereses de los grupos de población a los que representaban?

\section{El Ayuntamiento en la resolución de conflictos}

Desde la Constitución de Cádiz se fijaron los asuntos en los cuales el municipio tenía el deber de intervenir. Con el tiempo, se fueron modificando en lo particular, pero en general se resumían en cuidar el bienestar y el desarrollo social y económico del municipio y de sus vecinos, conservar el orden público y procurarse recursos por diferentes medios, todo ello basándose en la normatividad de las ordenanzas municipales. ${ }^{40}$

En Chiapas, la Ley reglamentaria de Ayuntamiento de 1825 reguló sus funciones mientras que nada se especificó en la Constitución de 1826, limitándose ésta a determinar las circunstancias que debían concurrir para que los pueblos conformaran Ayuntamientos y las características de los electores y electos para empleos municipales. En 1858, sin embargo, la nueva Constitución estatal, en su artículo. 63, definía las siguientes funciones de la institución: ejecutar las leyes y recaudar las contribuciones e impuestos generales del Estado que les cometan las leyes; acordar toda obra de utilidad pública local y los arbitrios ó fondos necesarios; cobrar los impuestos municipales que acuerde y sean aprobados por el Congreso, invirtiéndolos en el objeto á que sean destinados; cuidar de las casas de beneficencia e instrucción pública y administrar los bienes comunales no comprendidos en la ley de desamortización; cuidar de la policía en todos sus ramos; cuidar de la tranquilidad, del orden y buenas costumbres; cuidar de los otros objetos de administración general y local que les designe las leyes, sin tomar parte jamás con carácter de Ayuntamiento en los asuntos políticos. Todas estas funciones son los asuntos que los esos gobiernos locales tuvieron que sortear en el día a día. No todas fueran conflictivas sino que formaban parte de los ámbitos en los que estaba obligado a intervenir, algunos de los cua-

\footnotetext{
a finales del siglo, en 1880, en un decreto ahora de Miguel Utrilla que trata sobre la misma obligación de alcaldes y funcionarios municipales de presentarse a tomar posesión de su encargo, bajo las penas que se impondrán a quien no lo haga, y dice además que "Los regidores que no asistan con puntualidad a sesión o no desempeñen sus comisiones, se les aplicará ipso facto por el presidente de cincuenta centavos a cinco pesos de multa". Archivo Municipal de San Cristóbal de las Casas, Chiapas, Decretos, Bulto 1887-1889, Expediente 16.

40 Ver Guzmán Pérez, Moisés: "Cádiz y el ayuntamiento constitucional en los pueblos indígenas de la Nueva España, 1820-1825”, en De súbditos del rey a ciudadanos de la nación, Universidad Jaume I, Castellón, 2002, pág. 313.
} 
les sí se convirtieron en un problema, sobre todo cuando los municipios se enfrentaban a situaciones críticas de índole social, política y económica.

Hubo otros conflictos que tuvieron un mayor peso en la vida diaria de esta institución. Algunos estaban provocados por la convivencia y el carácter pluriétnico de los pueblos y por la naturaleza - composición- del Ayuntamiento. La cuestión territorial fue especialmente problemática, es decir, sobre quiénes y en qué territorio ejercía su jurisdicción y autoridad, lo cual motivó que, en ocasiones, un núcleo de población solicitara su reconocimiento como municipio. ${ }^{41}$ Igualmente conflictivo se volvió el control de los recursos económicos, tanto por la forma en que se dotó de fondos a los municipios, echando mano de los bienes comunes de los antiguos pueblos de indios, como por la cuestión de las tierras, provocando un enfrentamiento entre las municipales y las comunales, y entre la propiedad privada y la colectiva. Muchos de estos problemas no eran nuevos en el siglo XIX, aunque se agudizaron por la nueva legislación. Podríamos pensar con esto, que el órgano de gobierno municipal fue una institución que en la mayoría de las ocasiones no respondía a los intereses de los pueblos indígenas.

Las diferentes Constituciones contenían las directrices generales de la administración de justicia en lo civil y lo criminal, además de otros cuerpos de leyes específicas en la materia; en algunos se especificaban las funciones jurídicas de los Ayuntamientos. Desde la de Cádiz, los alcaldes eran competentes en estos asuntos, a los que se les daba la categoría de conciliadores, ante quienes los demandantes "por negocios civiles o por injurias" deberían presentarse con la clara intención de arreglar el asunto en esta instancia "extrajudicial", y sin cuyo trámite no se iniciaría pleito alguno, en caso de no solucionarse la demanda en esta instancia. ${ }^{42}$ En Chiapas, diferentes decretos del Congreso Constituyente de 1825, también diseñaron el marco legal para la administración de justicia por la entidad local, igual que la Ley reglamentaria de Ayuntamiento del mismo año, en la que los alcaldes seguían ejerciendo el cargo de conciliadores, "sin perjuicio del decreto de 16 de junio con respecto a los que ejerzan la primera instancia". ${ }^{43}$

41 Escobar muestra para el caso de las Huastecas que a menudo no coincidía el territorio indio con la jurisdicción del Ayuntamiento y con frecuencia el origen de los conflictos fue la nueva relación entre cabeceras y pueblos sujetos. Escobar Ohmstede: "Del gobierno indígena...", págs. 14 y siguientes.

42 Artículos 282, 283 y 234 de la Constitución de Cádiz.

43 AHE, Fondo Archivo Histórico de Comitán, Presidencia municipal, Ley reglamentaria de Ayuntamiento. 1825. El decreto al que se refiere es el Número 33 de los Decretos del Congreso Constituyente, que contenía varias disposiciones con respecto al arreglo de los Juzgados. Colección de Decretos del Congreso Constituyente de las Chiapas. Tomo 1. ${ }^{\circ}, 1828$. Decreto núm. 52 (Recurso electrónico: Biblioteca Digital Daniel Cosío Villegas. Web: http://biblio2.colmex.mx/bibdig/chiapas001/ base1.htm 
Sin embargo la Constitución estatal de 1826 se limita a regular el funcionamiento del poder judicial, ejercido por la Suprema Corte de Justicia y los demás tribunales del Estado, refiriéndose en este caso a los jueces de primera instancia y a los asesores, es decir, los alcaldes primeros de los pueblos cabeceras de partido, desapareciendo de ella cualquier alusión a la relación de los Ayuntamientos del resto de los municipios con la resolución de conflictos que, imaginamos, estaría regulada por los decretos del Congreso. Posteriormente, la Constitución del Estado de Chiapas de 1858 depositaba el ejercicio de la justicia en los alcaldes, como juzgado inferior y como última instancia después del Tribunal de Justicia, y los jueces de primera instancia. En la de 1893, ya se reconocía a los jurados y los jueces menores, además de los anteriores, como órganos de impartición de justicia.

Las acusaciones de deudas, los abusos de unos individuos sobre otros, que se volvían más problemáticos cuando se trataba de los abusos de los ladinos sobre los indígenas, o los malos tratos físicos son los casos más comunes en los que los Ayuntamientos se convirtieron en jueces de los conflictos surgidos entre los individuos o comunidades. En estos asuntos, aunque tenían las facultades como juzgados locales para juzgar y castigar el delito, la recurrencia a instancias superiores fue frecuente, dependiendo de la gravedad del caso, ya que los Ayuntamientos de los municipios estaban sujetos a los juzgados de primera instancia. También se dio el caso inverso, es decir, que los casos presentados en éstos últimos se turnaran a los jueces locales para su resolución. Un ejemplo: el juzgado de primera instancia del departamento de Chilón, turnó al alcalde primero de la villa de Ocosingo el caso de Lucía de la Cruz, sirvienta del ciudadano Manuel Salazar, que

...se presentó a las seis de esta mañana en la casa de mi habitación solicitando de mi autoridad la separación de la casa del dicho señor al mismo tiempo quejándose de malos tratos recibidos por la señora esposa de Salazar. Y encontrándose este juzgado con atenciones urgentes ha dispuesto consignarlo como lo consigna al digno juzgado de usted para que obre en justicia y de conformidad con las leyes relativas que trata de estos casos...Ocosingo abril 6 de $1877 .{ }^{44}$

Un asunto en el que intervino el cuerpo municipal fue en los problemas ocasionados en las relaciones laborales con respecto a la mano de obra indígena. Jan Rus argumenta que uno de los problemas que tuvo el desarrollo de las grandes fincas de café a finales del siglo XIX fue la escasa posi-

44 AHE, Fondo Castañón y Gamboa, Expediente 555, Legajo de oficios de Chilón de 1877. 
bilidad que tenían para acceder a los trabajadores que las beneficiaran. ${ }^{45}$ Como ya había sucedido durante la colonia, los Ayuntamientos de los pueblos indígenas se vieron obligados a organizar el flujo de mano de obra hacia las grandes fincas. Sin embargo, también actuaron de "intermediarios" en la resolución de los conflictos que surgían entre los sirvientes y sus amos o con otras personas. Así, tenemos varios ejemplos de pleitos turnados a los juzgados locales por quejas de deudas de los trabajadores, como el que dirige el juzgado primero del departamento de Chilón al alcalde primero de la villa de Ocosingo, que a la letra dice:

El indígena Manuel Rodríguez, del vecindario de Sivacá, se ha presentado ante este juzgado manifestando que su amo don Manuel Andrés Parada al darle recibo de desacomodo le hace pagar partidas que dice el quejoso no haberlas tomado a su cuenta y en su consecuencia prevengo a usted que atienda en pronta y recta e imparcial justicia al citado indígena Manuel Rodríguez, averiguando si las partidas que constan en el libro son legales... Ocosingo, julio 27 de $1877 .{ }^{46}$

\section{El Ayuntamiento, de juez a parte de los conflictos}

Por último nos detendremos en otros casos de justicia en los que intervino el cuerpo municipal. Son aquellos en los que el Ayuntamiento dejó de ser juez, para convertirse en parte de los conflictos, es decir, las actuaciones de las municipalidades ladinas, indias o mixtas en los procesos que afectaban a sus intereses o los de sus vecinos, independientemente de su calidad étnica. Aquí pondremos especial atención a las estrategias que usaron los indígenas en casos de conflictos. ${ }^{47}$

45 Rus, Jan: "El café y la recolonización de los Altos de Chiapas, 1892-1910", en Olivera, Mercedes y Palomo, María Dolores (coords.): Chiapas: de la Independencia a la Revolución. CIESASConsejo de Ciencia y Tecnología del Estado de Chiapas, México, 2005, págs. 253-287.

46 AHE, Fondo Castañón y Gamboa, Expediente 555, Legajo de oficios de Chilón de 1877.

47 Fueron varios los métodos que utilizaron para evadir la legislación en unos casos, o ponerla a su favor en otros, además de otras estrategias para impedir el despojo de las tierras. Algunos autores han trabajado sobre procesos similares en Michoacán, como Purnell, Jennie: “'Con el debido respeto'. La resistencia popular a la privatización de tierras comunales en el Michoacán del siglo XIX”, en Roth Seneff (ed.): Recursos contenciosos..., págs. 85-128; Escobar Ohmstede, Antonio: "Los condueñazgos indígenas en las huastecas hidalguense y veracruzana: ¿defensa del espacio comunal?", en Escobar Ohmstede, Antonio: Indio, nación y comunidades en el México del Siglo XIX, Centro de Estudios Mexicanos y Norteamericanos-CIESAS, México, 1993, págs. 171-188, analiza la formación de condueñazgos en la Huasteca como una de esas vías; Edgar Mendoza García (Los bienes de comunidad y la defensa de las tierras en la Mixteca Oaxaqueña, Senado de la República, México, 2004) hace lo propio en la Mixteca Oaxaqueña y señala que los indígenas lograron conservar por medios legales e ilegales sus tierras y bienes comunales, mostrando a la vez su importancia económica para la institución municipal. 
Sin pretender centrarnos exclusivamente en procesos y pleitos relacionados con las tierras de los pueblos y la defensa de los bienes comunes, podemos afirmar que estos casos son un excelente campo para ejemplificar la situación que pretendemos analizar. La ideología liberal, en aras de la civilización y para sacar a los indios de su apatía en cuanto a la producción, ${ }^{48}$ fomentó de forma paulatina la desaparición de la propiedad comunal a favor de la propiedad individual, ${ }^{49}$ lo que permitió que un número cada vez mayor de población ladina accediera a las tierras de los pueblos. Ello provocó varios enfrentamientos, como los ejemplos que mostramos a continuación.

\section{El pleito por el ejido de Zapaluta: defensa de los recursos municipales}

La legislación decimonónica protegió la existencia de los ejidos. ${ }^{50}$ En diferentes decretos de las décadas de los veinte a los cuarenta se estableció que los Ayuntamientos eligieran y midieran sus dos porciones de ejido antes de cualquier medida de particulares en la zona; la cantidad de tierras ejidales estaría determinada por la población que tuviera el pueblo, y éstas deberían ubicarse dentro de la jurisdicción de cada uno de ellos. ${ }^{51}$

Las indefiniciones en cuanto a las medidas de los ejidos, lo largo de los procesos de adjudicación y, en general, las artimañas que los ladinos usaron para obtener propiedades provocaron abusos y usurpaciones de tie-

48 Desde los inicios de la época colonial, había sido opinión generalizada que los indígenas producían únicamente para el autoconsumo, por lo que había una gran apatía en ellos. El panorama de inicios del siglo XIX puede consultarse en Bonilla Bonilla, Adolfo: "Matías de Córdova en el contexto del pensamiento económico y étnico ilustrado centroamericano", en Olivera y Palomo (coords.): Chiapas: de la Independencia..., págs. 215-229.

49 A partir de las Cortes de Cádiz, la política agraria se dirigió en este sentido. El decreto de 4 de enero de 1813 "disponía el fraccionamiento de los terrenos comunales, excepto los ejidos". Cortés Máximo, Juan Carlos: "La comunidad de Tarímbaro. Gobierno indígena, arrendamiento y reparto de tierras, 1822-1884", en Paredes Martínez, Carlos y Terán, Marta (coords.): Autoridad y gobierno indígena en Michoacán, 2 tomos, El Colegio de Michoacán-CIESAS-Instituto Nacional de Antropología e Historia-Universidad Michoacana, Zamora, Mich., 2003, pág. 442. Diferentes leyes a lo largo del siglo XIX fueron convirtiendo la propiedad comunal de los pueblos en propiedades privadas.

50 Sobre la conformación de los ejidos en Chiapas, puede consultarse el trabajo de Pedrero Nieto, Gloria: "La evolución del ejido en Chiapas (siglo XIX)", en Olivera y Palomo (coords.): Chiapas: de la Independencia..., págs. 339-366.

51 Gobierno del Estado de Chiapas: Colección de leyes agrarias y demás disposiciones que se han emitido con relación al Ramo de Tierras, Imprenta Joaquín Armendáriz, sin lugar, 1878, citado por Fenner, Justus: "La defensa de las tierras colectivas en Chiapas, 1876-1900. Denuncios registrados en el Juzgado de Distrito de Chiapas", documento manuscrito. 
rras en los pueblos por parte de particulares, que desembocaron en enfrentamientos y pleitos cuyos protagonistas fueron los Ayuntamientos actuando en defensa de los intereses de los pueblos. ${ }^{52}$ Aunque del análisis de los "denuncios" se deduce que se cuestionaba la personalidad jurídica de los Ayuntamientos como representantes de los pueblos en estos juicios, en la mayoría de los casos aparece el Concejo municipal como parte defensora de los intereses comunes de los vecinos.

Los pleitos también ilustran las diversas formas de defensa que los indígenas de Chiapas idearon para proteger sus intereses, bien comunales o bien particulares, a través de acciones colectivas o individuales y en muchos de los casos aprovechando el espacio que la legislación, la justicia y las instituciones les proporcionaban. Así la ideología liberal no pudo acabar con el carácter colectivo de las sociedades indígenas que, sin embargo, no dudaron de echar mano del individualismo cuando la situación lo requería.

El 20 de mayo de 1861, el procurador síndico del pueblo de Zapaluta, cuyos vecinos eran en su mayoría indígenas, se dirigió al jefe político del Departamento de Comitán en nombre de la población que representaba, para reclamar la segunda parte de su ejido que por ley le correspondía, ya que hasta ese momento sólo se le habían concedido "catorce caballerías poco más o menos no porque no hubiere de donde darle sino por morosidad del síndico y Ayuntamiento que en ello entendió". ${ }^{53}$ Los argumentos de la solicitud se remitían a la utilidad pública, ya que el pueblo de Zapaluta "como muchos del estado subsiste de la labranza y crianza", para lo cual le era indispensable la parte de ejido que le correspondía. Además, debido a "la falta de éste la clase indígena se está direccionando en las haciendas circunvecinas sufriendo con esto grave perjuicio". Solicitaba asimismo que la parte de ejido se la dieran cerca de una montaña por "estar inmediato al pueblo y a la primera porción del ejido de éste", vecina de las haciendas Santa Rita y San Isidro "de cuyos dueños recibe ese vecindario... muchos perjuicios".

El gobierno del Estado autorizó la solicitud del pueblo de Zapaluta y pidió que se midieran los terrenos; fue en este trámite cuando comenzaron los problemas con los vecinos, ya que surgieron desacuerdos en cuanto a la

52 El archivo del Juzgado de Distrito de Chiapas contiene una gran cantidad de estos juicios promovidos a causa de los denuncios de tierras baldías, sobre todo a partir de las Leyes de Reforma.

53 Por el art. $2 .^{\circ}$ de la ley 28 de enero de 1847 , le correspondía "una legua cuadrada a los pueblos que tengan un mil habitantes abajo". En adelante, en este apartado, todas las citas textuales referentes a este caso, si no se indica lo contrario, están tomadas del expediente "Juicio de oposición sobre el mejor derecho al terreno denominado Achasetic seguido entre el ayuntamiento del pueblo de Zapaluta y el Sr. Gregorio Culebro”. AJD, Sección Civil, Caja 1, año 1861 
delimitación de lo que era la propiedad del ciudadano Gregorio Culebro, ladino, y lo que eran los terrenos nacionales, de donde podía concederse la segunda parte del ejido. Este fue el motivo de un largo y tenso pleito entre el Ayuntamiento de Zapaluta y Gregorio Culebro por "seis caballerías y pico...", quien no sólo alegaba propiedad sobre los terrenos, sino también que los vecinos del pueblo le perjudicaban constantemente, al introducirse en él para sacar leña y maderas. Esto llevó a la presentación de alegatos por ambas partes ante el gobierno político del Estado, en la que el Aayuntamiento de Zapaluta tuvo una intervención decisiva en defensa de los intereses del pueblo, rebatiendo con argumentos muy sólidos todos los que presentó el señor Culebro.

En marzo de 1866, aún no había salido una resolución del caso, por lo que nuevamente el Ayuntamiento nombró a un comisionado para dirigirse al gobierno del Estado solicitando justicia, que en este caso apoyó a Zapaluta, en virtud de la necesidad de tierras que tenía el pueblo. Como la resolución no fue respetada, se reavivó la polémica con la continuación de un pleito, incluso después de la muerte de Gregorio Culebro. Los vecinos se veían privados de la extracción de recursos del terreno por parte del representante de los herederos del susodicho ciudadano. Así, el 26 de marzo de 1867, el gobierno libró una orden para que la jefatura política hiciera lo conducente para que no se privase a los vecinos de Zapaluta hasta que la autoridad judicial determinara quien tenía el derecho al terreno. ${ }^{54}$

Finalmente, en marzo de 1872, Manuel Antonio Guillén, presidente municipal de Zapaluta, expuso que ante la indefinición de la situación del terreno habían surgido problemas, que habían puesto en peligro la vida de los vecinos del pueblo, ya que "el mayordomo y mozos del español don Ángel de la Vega les impiden a mano armada la extracción de madera, leña y otros artículos de uso común de la misma montaña". ${ }^{55}$ Por ello puso una demanda con la que pretendía, en primer lugar, que se declarara que los terrenos eran propiedad del pueblo de Zapaluta; que debido a que durante tanto tiempo se le había impedido a los vecinos su uso, solicitaba que se recompensara al municipio por los perjuicios sufridos; por último, pedía que se impidiera al señor Vera el uso de los terrenos y se le condenara a pagar las costas del proceso, como heredero de Gregorio Culebro. ${ }^{56}$ Desafortunadamente, el expediente no contiene la resolución final del caso,

54 Ibidem, "Expediente de concesión de los ejidos del pueblo de Zapaluta. 1861".

55 Ibidem.

56 Ibidem. 
pero lo que nos interesa resaltar es la constante e intensa defensa que el Ayuntamiento de Zapaluta realizó contra todo aquel que pretendiese privarlo de lo que, bajo su punto de vista, le correspondía al pueblo.

\section{El asunto de Pueblo Nuevo Solistahuacán: el papel de las autoridades tradicionales}

En este mismo sentido, podemos ver otros casos en los que sale a relucir un enfrentamiento entre ladinos e indígenas por la defensa de sus derechos. El ciudadano Francisco Hidalgo, vecino de Jitotol, denunció el terreno nombrado el Cerro del Campanario, en Pueblo Nuevo Solistahuacán, departamento de Simojovel. Se citó dos veces al Ayuntamiento de ese pueblo para que compareciera a manifestar si la denuncia afectaba sus intereses. En la segunda ocasión, el 15 de mayo de 1861 comparecieron las autoridades municipales junto con los ciudadanos Tomás Alegría y Tomás Jiménez, ancianos y vecinos, a quienes se les informó de la denuncia del terreno del Cerro del Campanario y se les preguntó sobre los intereses que tenían en él. De la demanda se deduce que el que a ellos les interesaba era el nombrado El Carrizal, "y que acaso será el que el señor Hidalgo quiere medir" y que si así lo hiciera

... resultarían perjudicados porque allí cortan maderas y mecate para reedificar su iglesia, convento, casa municipal y para construcción de sus casas... que allí cogen leña para su gasto ordinario y piedra para hacer cal,... además tendrán que sufrir los perjuicios que les ocasionarían los ganados que el señor Hidalgo ponga porque está lindando el terreno indicado con la pequeña porción de ejido que circunvala su pueblo. ${ }^{57}$

En apoyo a estos argumentos, el presidente municipal de Jitotol dijo que los naturales de Solistahuacán quedarían privados de poder cortar leña y otros materiales que utilizaban para construir sus casas y demás edificios, "pues aunque dichos materiales los haya en otros lugares están bastante lejos del pueblo". ${ }^{58}$ Esta declaración fue razón suficiente para que el agente del Ministerio de Fomento no autorizara la enajenación de los terrenos que habían sido denunciados. Lo interesante de este caso son dos hechos:

57 Ibidem, años 1857-1859, "Denuncia que el C. Francisco Hidalgo hace del terreno nombrado El Cerro del Campanario, Pueblo Nuevo Solistahuacán".

58 Ibidem. 
en primer lugar, muestra que la justicia no estranguló a los pueblos y sus habitantes hasta tal punto de dejarlos en la miseria. En segundo, debemos resaltar la presencia de los ancianos de Pueblo Nuevo Solistahuacán, quienes fueron convocados para opinar acerca de los perjuicios que les podría causar la denuncia referida. El cuerpo o Consejo de ancianos era una institución con un gran peso político en los pueblos indígenas de Chiapas. No formaban parte de la estructura de los Ayuntamientos, pero gozaban de una gran autoridad entre los de su misma clase. Ellos formaban parte de los gobiernos indios y en los casos que afectaban a la comunidad siempre estaban presentes para intermediar por los intereses del común.

\section{La hacienda San Pedro Pedernal de Huistán: el uso del derecho positivo como estrategia de defensa de los bienes comunes}

Un último caso que incluimos en este trabajo es el que se desarrolló en Huistán, sobre la hacienda San Pedro Pedernal, en el que la resistencia y la lucha colectiva de los indígenas de este pueblo se desarrollaron a través de mecanismos legales. ${ }^{59}$ El pleito tuvo lugar entre cuatro indígenas de Huistán -Miguel Santis, Miguel Méndez, Domingo González y Pascual Álvarez-, quienes en 1829 habían comprado en propiedad particular la finca San Pedro Pedernal, y los hermanos Isidro y Ciriaco Aguilar, ladinos, quienes pretendían quedarse con la hacienda. ${ }^{60}$ Éstos últimos argumentaban que los indígenas la habían comprado no para ellos sino para el común, con dinero que previamente habían recaudado entre todos los vecinos. Es muy posible que los hermanos Aguilar estuvieran en lo cierto, ya que el ganado de la cofradía de Nuestra Señora de la Luz de este pueblo se custodió en años posteriores a su compra por los cuatro indígenas en esta hacienda "que es finca de la pertenencia del común de este pueblo". ${ }^{61}$

59 Este caso está más desarrollado en Palomo Infante, María Dolores: "Enredos y sutilezas del derecho en defensa de los bienes comunes. La hacienda San Pedro Pedernal de Huixtán, Chiapas. 17901865", Revista Pueblos y Fronteras digital, Núm. 3. [Monográfico sobre Tierra y población en el Chiapas decimonónico] Programa de Investigaciones Multidisciplinarias sobre Mesoamérica y el Sureste-Instituto de Investigaciones Antropológica-Universidad Nacional Autónoma de México, San Cristóbal de las Casas, Chiapas, México, 2007. Dirección: http://www.pueblosyfronteras.unam.mx

60 AHJSC, Inventario 1. Expediente 2444. Año 1879. Escritura de compromiso entre Farrera y Duguelay.

61 Archivo Histórico Diocesano de San Cristóbal de las Casas, Chiapas. Libro de la cofradía de Nuestra Señora de la Luz. Huistán. 1790-1847. 
El 1. ${ }^{\circ}$ de septiembre de 1826 se había publicado una ley sobre terrenos baldíos, cuyo artículo $1 .^{\circ}$ ordenaba que "todos los terrenos baldíos o nacionales y de propios excepto los ejidos necesarios de los pueblos, se reducirán a propiedad particular", ${ }^{62}$ lo que se convirtió en una amenaza para las tierras comunales, ya que abría la posibilidad de que cualquier persona pudiera reducir a su propiedad los terrenos baldíos y de propios de los pueblos. Así, los indígenas del pueblo de Huistán temían que sus tierras comunales fueran objeto de las leyes y perderlas en cualquier momento. La propiedad de la hacienda podría sustituirlas llegado el caso; además, con su compra adquirían más terrenos en "propiedad particular", amparados en la ley. En realidad, los indígenas que la compraron sólo serían prestanombres en la transacción.

En 1851 la hacienda se arrendó a Ciriaco Aguilar. En la celebración de este contrato surgió la primera polémica, en la que es interesante analizar la actuación del cuerpo municipal, que en este momento era mixto, y de otras autoridades - alcalde primero y los demás municipales indígenas-, quienes en todo momento defendieron la propiedad particular de los cuatro indígenas y argumentaban que el Ayuntamiento no podía realizar este contrato; no obstante, el presidente municipal, que era ladino, estaba a favor de su arriendo, para obtener recursos destinados a la educación primaria del pueblo. Finalmente se hizo el arrendamiento por una orden de la Prefectura.

Años más tarde, el mismo Aguilar denunció a la hacienda amparado en la ley Lerdo, ya que según él tenía el carácter de corporativa por pertenecer al Concejo municipal de Huistán y por lo tanto estar sujeta a estas leyes. El denunciante argumentaba que era del Ayuntamiento porque con él había celebrado el contrato de arrendamiento. Fue aquí donde surgió el conflicto, en el que se entrelazan los intereses de los indígenas que la compraron, los del común del pueblo de Huistán y el Ayuntamiento y los de Ciriaco Aguilar; es donde entran en juego el cruce entre la legislación, los procesos judiciales y las estrategias de defensa. Nuevamente el gobierno local salió en defensa de los intereses comunes del pueblo, cuando el alcalde primero y el síndico indígena volvieron a apelar a la propiedad particular de los cuatro vecinos para salvaguardar la posesión de los terrenos y evitar que cayeran en manos de los ladinos.

62 Colección de las leyes agrarias 1878: 3-5, citado en De Vos, Jan: Vivir en frontera: la experiencia de los indios de Chiapas, CIESAS-Instituto Nacional Indigenista, México, 1997, pág. 250. 
A lo largo del proceso, hubo algunos detalles que demuestran la perfecta estrategia que utilizaron los indígenas de Huistán. Por ejemplo, en el pleito evitaron en todo momento pronunciar la palabra comunidad, concepto muy discutido en la época. La actuación del asesor fue fundamental, por lo que podemos comprobar que los indígenas recurrieron a todos los medios legales a su alcance. Dicho asesor basó su defensa en el único instrumento que podía salvar la propiedad de las manos de los ladinos: la escritura de propiedad de los cuatro indígenas que la habían comprado en 1829.

\section{Conclusiones}

De acuerdo al análisis y casos presentados, vemos que la población indígena no fue un objeto manejado en los procesos históricos decimonónicos. Los cambios institucionales de carácter político que se produjeron a nivel local con el paso de la vida colonial a la independiente afectaron a toda la población, sin importar su calidad étnica. Por supuesto, los indígenas se vieron en desventaja en bastantes ocasiones, sobre todo teniendo en cuenta que ya no estaba vigente la protección que les brindaban las Leyes de Indias. Enfrentarse a la legislación liberal, y sobre todo, a las acciones particulares de los ladinos, los ponía en una situación desventajosa y fue un proceso difícil de afrontar.

Sin embargo, en los municipios, tanto individual como colectivamente, la población indígena supo posicionarse frente a los ladinos y frente al Estado, por diferentes vías. Concretamente, con las situaciones que hemos analizado, podemos llegar a algunas conclusiones sobre estos mecanismos o estrategias utilizados. Por una parte, se conformaron otras estructuras de poder entre los indígenas: sus justicias o autoridades tradicionales, que llamamos ahora, que se constituyeron en los intermediarios entre las instancias político-administrativas locales ladinas y estatales y la población indígena, como defensores de los derechos de éstos últimos. Por otra parte, en los Ayuntamientos considerados como ladinos, se incorporaron algunos miembros indígenas, como representantes de estos últimos.

La experiencia decimonónica no era nueva. Recordemos que los indígenas, que habían visto alterada su organización social con el sistema colonial, se empeñaron con todas sus fuerzas en rescatar lo recuperable de su antiguo sistema a través de la recreación cultural, a veces en nuevos espa- 
cios; y/o reestructurarlos mediante varios mecanismos para adaptarse a la nueva y cambiante situación. Para conseguirlo, buscaron nuevos ámbitos donde hacerlo, a veces incluso en espacios que el propio sistema colonial les brindaba.

Esto en relación a los mecanismos propios que desarrolló la población indígena para resistir o defenderse. Pero hubo otros que no son tan autónomos o propios, sino que se relacionaron con el desarrollo de las instancias de gobierno y administración y con el de la justicia y legislación. Los indígenas, sobre todo los de las elites, conocían a la perfección los derechos que las leyes daban a los individuos, de los cuales se agarraron para no quedar desprotegidos, a veces de forma individual, otras de forma colectiva. Justus Fenner asegura que del análisis de los resultados obtenidos en los denuncios de tierras baldías se aprecia una "estricta aplicación de las leyes vigentes en la materia por parte de los jueces". ${ }^{63}$ Asimismo, a menudo encontraron en las autoridades políticas estatales y municipales instituciones en las que apoyarse para defenderse de los casos de injusticia. Podemos ver en los procesos judiciales que en bastantes ocasiones apoyaban, si no es que favorecían, a la población indígena y sus derechos como individuos; incluso poco después de mediado el siglo, el mismo gobierno del estado de Chiapas creo, en 1869, la figura del protector de indios, con facultades para oír las quejas de éstos; “deducirá ante los Tribunales competentes las acciones civiles o criminales que les correspondan, y sostendrá sus derechos vigorosamente por todas las vías legales que se abran para su defensa", sin que ningún juzgados ni tribunales del Estado pudiera "pronunciar sentencia definitiva, ni auto interlocutorio que tenga fuerza de tal, sin oírse previamente al protector de indios." 64 Aún en los Ayuntamientos "ladinos" que, como hemos visto, fueron un órgano para la resolución de conflictos, la población indígena encontró mecanismos de defensa. Con ello no queremos decir que las leyes y las instituciones actuaran a favor de los indígenas, impensable para la época, sino que ellos supieron aprovechar cada resquicio que se les presentaba.

Recibido el 14 de octubre de 2008 Aceptado el 7 de enero de 2009

63 Fenner, "La defensa de las tierras..."

64 AHE, Fondo Castañón y Gamboa, Expediente 404 (1869-1870). 